\title{
5 \\ DESIGNING THE COLLABORATION AND ITS OPERATIONAL FRAMEWORK
}

\section{Introduction}

It is important to ensure that the collaboration model is fit for purpose. That said, collaboration is not always the 'answer' and can sometimes look very much like a solution in search of a problem. In this chapter, we look to the collaboration literature and to the experiences of people in our case studies for guidance about designing successful multiparty collaborations.

Collaboration needs more than good intentions; it also needs to be designed, built and implemented. Collaborations have many moving parts; ensuring that the operational framework for the collaboration is fit for purpose is a core design challenge. Attention to the character-and history-of stakeholder relationships is critical, as is attention to the degree of fit (or lack of fit) between legacy systems, operating norms and formal rules. For not only do each of the collaboration partners and stakeholders bring their own, often distinct, institutional and administrative histories to the table, they also have diverse perspectives and interests that affect how collaboration works. Purposive design of the collaboration framework can address such differences head-on and provide the basis for a new synthesis: a renewed understanding of the problem and what needs to be done. 
Collaborations work best when there is clarity about aims, strategy, process, communication and conduct. However, respectful, cordial communication can sometimes be difficult, especially when strong personalities are involved and/or parties bring divergent views to the table (Kahane 2017). It is essential, therefore, that collaboration partners forge a shared understanding of the collaboration's purpose, objectives, rationale, strategic direction and proposed actions, based on a common language. It is important to identify the things on which collaboration partners agree and those on which they disagree. Where there is disagreement, it might be possible to establish protocols to guide discussion and so avoid conflict and fallout. Independent collaboration brokers can play a positive role by helping to bridge gaps and resolve conflicts in nomenclature and understanding.

It is important to acknowledge that all collaborations are highly context dependent and, in some ways, unique. Collaborative strategies need to be built on a comprehensive understanding of the presenting problem(s) and the social, political and policy ecologies in which they arise. Typically, the kinds of problems that collaboration seeks to address tend to be multifactorial in nature and do not fall wholly within the responsibilityor capability — of any single entity or jurisdiction. Nor are they amenable to resolution by multiple entities or jurisdictions acting separately because the interstices of bureaucratic and programmatic boundaries are where people and communities can fall through the cracks.

\section{Collaboration is about hope}

Despair is a natural and understandable reaction to complex-or 'wicked'-problems. It is easy to become resigned to a status quo that is demonstrably not achieving the desired results. It is altogether too easy to arrive at an acceptance that systemic, institutional and cultural barriers to change are insurmountable. In part, this is a product of path dependence-a process in which decisions made in the present context are shaped by the legacy of past decisions, even when past circumstances are no longer relevant. Path dependence can explain why it is sometimes difficult for policymakers and practitioners to think outside the square and visualise alternative ways of working. Equally, complexity-and its bedfellows, fragmentation, incoherence and uncertainty-also creates 
opportunities for path creation, which is a process in which actors look to the past, not necessarily to repeat or avoid what happened previously, but, instead, to generate new options (Garud et al. 2010).

In New Zealand, the local Children's Team in Gisborne coined the term 'too many cars in the driveway' to give expression to the frustrations of families and communities in crisis who had long struggled to make sense of, and get help from, the multiple agencies and officials involved in their lives. We strongly suspect that, for many frontline workers, 'too many cars in the driveway' is a potent metaphor for ineffective systems and lost opportunities. In Gisborne, it provided a rallying cry to create greater coherence, provide clear entry points and pathways, reduce administrative duplication and gaps/inconsistencies in service delivery and generally provide a platform for bespoke responses to complex problems.

To be sure, 'complexity' entails challenges on multiple fronts: political, operational, informational and institutional (among others). Challenges can also present opportunities; there is fluidity in complexity that creates spaces for innovative, disruptive solutions to complex problems. A large part of the collaboration challenge is often about how best to leverage 'complexity' and 'interests' to mobilise support for a collaborative approach. There can also be an element of serendipity about collaboration: collaborative responses sometimes arise from a fortuitous collision of interests.

\section{Be clear about the problem and demonstrate the case for collaboration}

Collaboration is only one of many strategies that might be utilised to leverage responses to complex social problems-responses that are fit for purpose. Deciding whether collaboration is the most appropriate strategy requires a clear understanding of the social, geographic and/or historical characteristics of the problem(s) to be addressed (see Chapter 9). Evidence about the nature and scale of the problem is critical, as is a plan for gathering evidence about the practical impact of any collaboration (see Chapter 3). Crucially, authorisers and prospective partners need to be provided with evidence that collaboration offers a necessary and viable catalyst for change. This might include evidence that existing attempts to address the problem have not been effective and are unlikely to be effective into the future. 
Bear in mind that collaboration is not always the appropriate solution to a problem. Some problems are amenable to relatively simple linear solutions and, sometimes, mandating collaboration can make problems more difficult than they need to be or even deflect effort away from the problem. Pell (2016), for example, argues against the pursuit of collaboration as a policy goal of government. She contends that focusing on collaboration 'joins up documents, not services' and does not of itself solve the problem of fragmentation; rather, it 'wastes money, fosters compliance and creates a new layer of bureaucracy' while the 'true cause of fragmented services goes unaddressed' (Pell 2016: 4).

Although Pell concedes that criticising collaboration is 'a little heretical', she suggests that when the interface between the citizen and the organisations they interact with' is examined empirically, one finds that 'specialisation, targets, thresholds and eligibility criteria cause fragmented services' (Pell 2016:5). According to Pell (2016:5), 'services are fragmented because we design them to be' and the priority for policymakers should be to reverse the functional design of public services to ensure they 'work for citizens and communities from their point of view'.

\section{Establish a lingua franca for collaboration}

It is essential to bear in mind that different stakeholders might bring to the table different understandings or framings of the problem, as well as different language, differing capacity and capability and different motivations or values. There is a broad consensus in the collaboration literature that it is important to establish a commonly understood language among the collaboration partners. This is especially relevant in collaborations that bring together practitioners from different disciplines. For example:

- Some stakeholders might attribute the causes of violence against women to poverty, dispossession, a lack of education or substance abuse, whereas others might look to broader historical or cultural reasons for the perpetuation of gendered violence.

- In the childhood obesity space, clinical practitioners-dieticians, general practitioners and community nurses-might tend to 'medicalise' the problem, whereas others might take a wider 'systems perspective' that accommodates a wider array of reinforcing factors including food industry practices, marketing, the cost and availability of healthy food options and public awareness. 
- In the disaster recovery space, many first responders will view the problem through the lens of a command structure concerned primarily with the deployment of physical assets, whereas others might see resilience as primarily a function of social cohesion and the mobilisation of 'soft' assets (social capital).

As well as having a common language to describe the problem, it is also essential to have a common language to describe the operational framework for collaboration. According to one of Australia's foremost collaboration experts, Robyn Keast (2016: 39-40), clarity of language is important because different understandings and expectations can lead to confusion and frustration, and potentially to dysfunctional or suboptimal outcomes.

\section{Devise an appropriate operational framework}

Keast (2016: 34) distinguishes between the various ways in which interorganisational relationships might be expressed in operational terms, and the subtle (and not-so-subtle) taxonomic differences between interorganisational entities such as amalgamations/mergers, alliances, networks, joint ventures, consortiums, coalitions and partnerships. These are summarised in Table 5.1.

Table 5.1 Summary of interorganisational entity features

\begin{tabular}{|l|l|l|}
\hline Term & Purpose/focus & Defining features \\
\hline $\begin{array}{l}\text { Amalgamation/ } \\
\text { merger }\end{array}$ & $\begin{array}{l}\text { Formed to achieve } \\
\text { efficiency }\end{array}$ & $\begin{array}{l}\text { Vertical coordination via hierarchical/ } \\
\text { formalised authority }\end{array}$ \\
\hline Alliance & $\begin{array}{l}\text { Joining of resources/forces } \\
\text { to meet a common purpose } \\
\text { (protection, trade) }\end{array}$ & $\begin{array}{l}\text { Limited number of partners (exclusive) } \\
\text { Close relations by affinity, similar } \\
\text { or shared interests (strong lock-in) } \\
\text { Pooling of resources } \\
\text { Incomplete contracts, detailed } \\
\text { negotiations and communication }\end{array}$ \\
\hline Joint venture & $\begin{array}{l}\text { Legal association for the } \\
\text { purpose of mutual profit }\end{array}$ & $\begin{array}{l}\text { Entity owned by two or more } \\
\text { independent entities } \\
\text { Variance in terms of legal basis } \\
\text { Can be a product of alliance }\end{array}$ \\
\hline Network & $\begin{array}{l}\text { Aggregate grouping of } \\
\text { (three or more) entities } \\
\text { around a common function } \\
\text { or task }\end{array}$ & $\begin{array}{l}\text { Based on flow of resources, and affect, } \\
\text { and cohesion of effort } \\
\text { Open system of interpersonal } \\
\text { relationship } \\
\text { Self-organising (loose lock-in) } \\
\text { Inclusive membership }\end{array}$ \\
\hline
\end{tabular}




\begin{tabular}{|c|c|c|}
\hline Term & Purpose/focus & Defining features \\
\hline Consortium & $\begin{array}{l}\text { Loose association for the } \\
\text { purpose of engaging in } \\
\text { a joint venture, working } \\
\text { together to achieve } \\
\text { chosen objective }\end{array}$ & $\begin{array}{l}\text { Interagency agreements, such as MOUs } \\
\text { Incomplete contractual agreements } \\
\text { Members responsible to others in } \\
\text { terms of agreed actions } \\
\text { Pooling of resources }\end{array}$ \\
\hline Coalition & $\begin{array}{l}\text { Temporary alliance formed } \\
\text { for the purpose of defence } \\
\text { against attack, advocacy, } \\
\text { to gain access/support }\end{array}$ & $\begin{array}{l}\text { Interagency agreements such as MOUs } \\
\text { Clear rules and operating principles } \\
\text { Temporary or time-limited arrangement }\end{array}$ \\
\hline Partnership & $\begin{array}{l}\text { a. Formal, legal } \\
\text { association for the } \\
\text { purpose of shared } \\
\text { profit/loss } \\
\text { b. Informal connecting } \\
\text { relationship }\end{array}$ & $\begin{array}{l}\text { Unincorporated } \\
\text { Smaller number of partners } \\
\text { Linked by written (formal) or verbal } \\
\text { (informal) agreements } \\
\text { Incomplete contracts } \\
\text { Time limited by agreement }\end{array}$ \\
\hline
\end{tabular}

Source: Keast (2016: 39).

Although there is often a strongly intuitive aspect to collaboration, as a purposive activity, it is essential for collaboration to be informed by logical, strategic thinking. Collaboration needs to be led-even if it utilises some form of distributed or shared leadership. The ways in which leadership is exercised need to be established and agreed among the partners. Protocols for communication and external representation need to be set out and adhered to. Behavioural expectations and processes for resolving disagreements need to be established. Systems for reporting achievements and measuring impact need to be devised. Agreements need to be reached about who does what. Collaborations also need an agreed framework for accountability and the management of risk (financial, legal, reputational and political). Above all, these functions need to 'work' for each of the partners. It might not always be possible to achieve a neat fit with the internal policies and business systems used by partner organisations, and some forbearance and flexibility will sometimes be required.

\section{Adaptivity and risk}

Two preconditions are implicit in any decision to engage in collaboration:

1. The recognition of a need to devise and navigate new ways of working (see Chapter 2).

2. Collaboration represents an attempt to work flexibly and adaptively in complex, uncertain and dynamic environments. 
Unfortunately, adaptive, flexible, person-centred processes are too often lacking in the typical operating environments of public sector organisations, where cultures of risk-aversion have long favoured standardised, rulesbased operating systems.

Organisations operating in the public sector often adopt a failsafe attitude to risk, which can significantly fetter collaboration partners and impair the achievement of collaboration aims. What collaboration in fact requires is a risk environment in which it is 'safe to fail' (Butcher and Gilchrist 2016: 372-73). The contrasting notions of 'failsafe' and 'safe to fail' were set out 45 years ago by Jones et al. (1975: 2):

Two poles on the spectrum of strategies are fail-safe and safe-fail. The goal of a fail-safe policy strives to assure that nothing will go wrong. Systems are designed to be foolproof and strong enough to withstand any eventuality. Efforts are made to radically reduce the probability of failure. Often the managers of such systems operate as if that probability were zero.

A safe-fail policy acknowledges that failure is inevitable and seeks systems that can easily survive failure when it comes. Rather than rely on reducing the occurrence of failure, this policy aims at reducing the cost of that failure.

It is important, therefore, for people participating in collaborative initiatives to ensure that authorisers understand that collaboration entails both uncertainty and risk, and to obtain their commitment to putting in place the expertise and resources to manage proportionate risk (not eliminate it). It is also important to accept the possibility of failure; and to clearly distinguish between 'blameworthy failure' (that is, failure that entails corruption, incompetence or unethical behaviour) and 'praiseworthy failure' (that is, things did not quite go as planned, but we can learn from the experience and do better in the future) (Edmondson 2011).

\section{An appropriate governance framework}

Often in multiparty collaboration, especially involving the public sector, there is academic concern about the constraining effect of path dependence and, in particular, the constraining effects of legacy rules, systems and processes in public sector agencies (Heuer 2011). To overcome this, it is important to consider the design of the collaboration architecture, including: 
- The instruments that will give effect to the collaboration-for example, an MOU, contract or other form of agreement.

- The process for reaching agreement about the nature of the problem to be addressed-for example, an investigation phase including consultations with stakeholders and relevant policy networks.

- The means by which the problem will be addressed-especially when a departure from past practices is contemplated.

- The respective contributions of the parties-including funding, information exchange and practical operational supports.

- The governance framework that will guide the collaboration-for example, a steering group, a governance group or some other form of oversight (Alam et al. 2014; Wilson et al. 2016).

Each of these elements can be set out in formal terms of reference (TOR). TOR provide a useful starting point for collaboration; however, if used as a compliance tool and applied in the form of 'rules', TOR can impede the realisation of collaborative purpose. It is important to allow the collaboration to make necessary adaptations as required by changing circumstances. This need not impair accountability so long as partner organisations are kept informed via the agreed governance framework about the emergence, extent and management of risk arising in the collaboration, and about required changes in operating procedures.

Trust-effective collaborations employ explicit strategies for the purpose of building trust, establishing credibility, confirming legitimacy and communicating the purposes of collaboration (Jupp 2000; Leat 2009; Bryson et al. 2009b; Corwin et al. 2012; Daymond 2015). However, trust can be hard to win because collaboration is often offered as an antidote to a history of policy failure and vexed relationships. Collaboration can struggle in the face of:

- cynicism: 'Everything else has been tried, why should this work?'

- impatience: 'We have been waiting a long time for signs of change; we want results now'

- doubt: 'Collaboration is all talk and no follow through'

- urgency: 'The situation is getting dire, do something quick'.

Each of these puts pressure on the collaboration advocates and leaders and accentuates the risk of collaboration failure. (See Chapter 10 for a more expansive exploration of trust, credibility and legitimacy.) 


\section{Collaboration is a way of thinking, not a model}

Effective collaborations have an organic quality; they are shaped and sustained by the relationships between partners and stakeholders. In short, collaboration is not an organisational model; it is a 'headspace'-a way of thinking and behaving. And, for this reason, it is unwise to unilaterally mandate a prescriptive model for collaboration. Although collaboration frameworks are expected to demonstrate accepted standards for operational performance, they should not be prescriptive policy artefacts. Our investigation leads us to conclude that, although all collaborations operate with a similar rationale, are obliged to address a similar set of practical and strategic problems and employ a similar suite of operational and governance disciplines, each collaboration is also unique in its own way in that it seeks to respond to a set of circumstances occurring in a unique context. And while collaboration partners remain accountable to their employing organisation (where relevant), it is also expected that they will exhibit fidelity to the purpose, aims and codes of behaviour established and agreed to by the collaboration partners.

Of course, many organisations do not exhibit collaborative behaviour internally, let alone in their relationships with external partners. It is reasonable to ask, therefore: 'If people can't work collaboratively within their organisations, what are the chances that they will be able to work collaboratively between organisations?' (see Chapter 7). Ultimately, a cultural predisposition for collaboration within partner organisations is likely to be a stronger predictor of successful collaborative relationships with external partners than the most elegantly crafted model.

\section{Don't forget silos}

The public sector is often accused of operating in policy and programmatic silos. These silos-reinforced by legal demarcation, budgetary appropriation and organisational culture-are blamed for the kinds of fragmentation and incoherence that plague the lives of disadvantaged and vulnerable people. Conversely, it is frequently asserted that the collaborative mindset is part of the DNA of the not-for-profit sector. The truth lies somewhere between the two: it is possible to find many examples of people in the public sector working effectively across organisational and sectoral boundaries (although they do so quietly and informally with no fanfare); and it is possible to find examples of intense rivalry between not-for-profit organisations. Although not-for-profit service-providing 
organisations often employ the rhetoric of partnership, their participation in the competitive human services market over the past three decades has somewhat muted the kind of collegiality that had been a hallmark of the sector (Butcher and Freyens 2011).

\section{'Zippering' as a means for bonding collaborators}

A 'zippered' relationship is one in which multiple people have multiple points of interaction with other entities and organisations. This can be contrasted with a 'button' relationship that relies on a single point of contact. Zippering applies both to the broader relationship strategies of organisations and to collaboration specifically. Effective partnerships require peer-to-peer connections at all levels of the organisation: executive to executive, middle manager to middle manager and coalface worker to coalface worker. Collaboration or partnership strategies utilising a 'button' approach run the risk that their primary point of contact: 1) might not have sufficient seniority or authority to influence decision-making or to make commitments on behalf of the partner organisation, or 2) might be unable or unwilling to transmit key messages about the collaboration/ partnership within the organisation. Zippering offers the best platform for assurance about organisational alignment with the purpose, aims and strategies proposed for the collaboration, and the best platform for achieving results. It also supports the vertical alignment of core understandings within the organisation as well as horizontal alignment between organisations. Bear in mind, however, that zippering might constitute a departure from 'business as usual'.

\section{Collaborative best practice}

It is possible to identify elements of better practice when designing a collaboration framework. These are set out in Table 5.2.

Table 5.2 Key elements of better practice when designing a collaboration framework

\begin{tabular}{|l|l|}
\hline Key element & Guide for collaborative best practice \\
\hline Purpose & $\begin{array}{l}\text { Work towards a clear, inclusive and shared understanding about aims, } \\
\text { strategy, process, communication and conduct. }\end{array}$ \\
\hline Communication & $\begin{array}{l}\text { Encourage clear, unambiguous, consistent, open and respectful flows } \\
\text { of information between all stakeholders. }\end{array}$ \\
\hline Expectations & $\begin{array}{l}\text { Ensure that expectations and goals are agreed and understood by all } \\
\text { stakeholders. }\end{array}$ \\
\hline
\end{tabular}




\begin{tabular}{|c|c|}
\hline Key element & Guide for collaborative best practice \\
\hline Evidence & $\begin{array}{l}\text { Compile documented evidence of the problem(s) being addressed and } \\
\text { previously attempted fixes (or failures). }\end{array}$ \\
\hline $\begin{array}{l}\text { Systems } \\
\text { mapping }\end{array}$ & $\begin{array}{l}\text { Build a comprehensive picture of the environment in which the } \\
\text { collaboration intends to operate, including the identification of key } \\
\text { systems, institutions, administrative bottlenecks, gaps, barriers, } \\
\text { stakeholders, influencers and gatekeepers. }\end{array}$ \\
\hline $\begin{array}{l}\text { Consult } \\
\text { stakeholders } \\
\text { and experts }\end{array}$ & $\begin{array}{l}\text { Comprehensively canvass the views of all relevant internal and external } \\
\text { stakeholders to identify potential synergies, sources of resistance, } \\
\text { untapped capacity and capability, conflicting perspectives, sources of } \\
\text { legitimacy and barriers to trust. }\end{array}$ \\
\hline $\begin{array}{l}\text { Authorising } \\
\text { environment }\end{array}$ & $\begin{array}{l}\text { Match collaborative rhetoric with formal authorisation; assess partner/ } \\
\text { stakeholder capacity and capability; identify and commit resources } \\
\text { (for example, funding, material support, reputation and information); } \\
\text { and confirm political and social licences to collaborate. }\end{array}$ \\
\hline $\begin{array}{l}\text { Executive/ } \\
\text { leadership } \\
\text { backing }\end{array}$ & $\begin{array}{l}\text { Ensure that the collaboration has clear and unambiguous backing by } \\
\text { the executive/leadership in each of the partner organisations/groups, } \\
\text { and that the executive/leadership understands the rationale, strategy, } \\
\text { time frame, resource implications and risks of collaboration-in other } \\
\text { words, make sure that authorisers know what they are signing up to. }\end{array}$ \\
\hline $\begin{array}{l}\text { Roles and } \\
\text { contributions }\end{array}$ & $\begin{array}{l}\text { Identify and agree to the respective roles played by partners/ } \\
\text { stakeholders and ensure these are understood and supported by } \\
\text { authorisers. }\end{array}$ \\
\hline $\begin{array}{l}\text { 'Zippered' } \\
\text { relationships }\end{array}$ & $\begin{array}{l}\text { Establish peer-to-peer relationships for the purpose of supporting } \\
\text { actions flowing from collaboration. }\end{array}$ \\
\hline $\begin{array}{l}\text { Collaboration } \\
\text { space }\end{array}$ & $\begin{array}{l}\text { Establish a curated-and protected-collaboration space governed } \\
\text { by operating procedures and decision-making frameworks agreed to } \\
\text { by collaboration partners and supported by authorisers. }\end{array}$ \\
\hline $\begin{array}{l}\text { Independent } \\
\text { facilitation }\end{array}$ & $\begin{array}{l}\text { Where appropriate, utilise independent collaboration brokers } \\
\text { to facilitate conversations about the shape of the collaboration; } \\
\text { these might include respected thought leaders or social-purpose } \\
\text { organisations and/or consultants with relevant expertise. }\end{array}$ \\
\hline Governance & $\begin{array}{l}\text { Create a governance framework for the purposes of providing } \\
\text { assurance to authorisers and stakeholders about the decisions, } \\
\text { actions and achievements of the collaboration. }\end{array}$ \\
\hline Sustainability & $\begin{array}{l}\text { Demonstrate executive sanction for collaboration leaders to participate } \\
\text { in decision-making forums and engage with stakeholders over the } \\
\text { long term. }\end{array}$ \\
\hline $\begin{array}{l}\text { Conflict } \\
\text { resolution }\end{array}$ & $\begin{array}{l}\text { Identify the things on which collaboration partners agree and the } \\
\text { things on which they disagree; acknowledge differences in priority and } \\
\text { perspective; and establish protocols to guide discussion and resolve } \\
\text { conflict. }\end{array}$ \\
\hline Futureproofing & $\begin{array}{l}\text { Futureproof collaboration by acknowledging the collective knowledge of } \\
\text { partners and stakeholders, leveraging corporate memory, undertaking } \\
\text { scenario-setting and succession planning, and documenting the } \\
\text { collaboration journey. }\end{array}$ \\
\hline
\end{tabular}




\section{What the cases tell us}

The collaborations we examined highlight the fact that every collaboration is different and there is, therefore, no stock standard approach. Identifying the ways in which collaborative efforts differ can inform the design of new collaborations. In principle, we would strongly advise anyone contemplating a collaborative approach to investigate a number of existing collaborations to understand their similarities and differences.

\section{A time and energy-intensive process}

In the establishment phase of collaboration, it is important to understand and manage the expectations of authorisers, partners, stakeholders and communities of interest. A consistent feature in each of the cases examined for this study was the skill with which collaboration leaders engaged in respectful conversations with a wide range of stakeholders about the purpose of the collaboration. Such conversations are not simply about informing; they are also about eliciting information and soliciting views, demonstrating a capacity to listen and to give weight to people's opinions.

Building relationships and trust and establishing shared expectations and procedural norms require significant upfront investments of time, effort and emotional energy. As one interviewee observed:

We realised, 'Gosh, just to set this up took way longer than we ever imagined', just getting people on board with the concept of it let alone to actually come together and work together and actually achieve some results ... That was one of the key learnings: collaboration takes time and continual energy from everyone. These are not words Treasury takes kindly to, and we really struggled to get their support. We had to compromise each budget cycle and got less and less funding each time. [It's] ironic of course that there are many other initiatives that also struggle to identify outcomes, but the reality was there was more political support for them and not so much for us.

Managing communications and flows of information to and from internal and external stakeholders is a particularly important practice element (see Chapter 8). Stakeholders and authorisers need to understand that building trust takes time:

I think one of the key messages that's been good for people is that it is a four to five-year journey. (Official, Children's Action Plan, New Zealand) 
Our core leadership group didn't really cement itself for at least 18 months, two years. By that stage, we've ended up with a really lovely breadth of people with some very diverse experience banks in there. (CBEM, Emerald, Victoria)

Sometimes, however, a level of trust needs to be established as a precursor to the sharing of information. More than one interviewee alluded to the political risk attached to information sharing:

Keep your minister safe. You cannot be the person at the front line who shares information ... There's nervousness at all levels of the system, because you don't want to be the one who ends up on the front page of the paper.

\section{The importance of evidence}

A capacity to offer evidence in support of a collaborative approach is essential to win support for collaboration from partner organisations and from external stakeholders who might be concerned about any change to existing systems and processes (even where existing systems are not working). Each of the examples in this study has supported the case for a collaborative approach with evidence about the nature and scale of the problem, and about the degree to which existing systems and programs have failed to demonstrate impact. Each has also been keen to demonstrate that collaborative approaches are impactful. While evidence about the nature and scale of the problem is crucial to winning institutional and community support for collaboration, evidence of failure of the status quo to address the problem is essential to sustain the formal authorisation and social licence that enable collaboration to occur (see Chapter 10).

\section{Demonstrating impact}

Authorisers and other stakeholders are often impatient for results and do not always appreciate that a definitive impact might not be immediately apparent (see Chapter 3). A senior official involved in the establishment of the Throughcare initiative in the Australian Capital Territory expressed some exasperation on this score:

I get annoyed sometimes about, 'Can you evaluate it? Can you tell us what's happening?' These things take time in terms of how you manage them. And it takes away the human context. 
This same official is credited with creating an authorising environment that allowed Throughcare to grow organically and with resisting pressure to set key performance indicators to avoid shifting the focus from collaboration to a fixation on deliverables.

Similarly, an official involved in the establishment of Children's Teams in New Zealand lamented that 'people expected results instantly'. She went on to point out, however, that collaborations cannot rely on anecdotal evidence for long:

We should have made our performance metrics way tighter ... we still would have struggled over time frames, but I'd now be able to give a clearer story based on the data rather than relying on anecdotal evidence for too long... We're starting to get way better at it, but we should have done better with this particular initiative by better managing our performance and the measurements associated with that.

\section{Importance of executive backing}

High-level backing is a critical ingredient for successful collaboration. The executives and leaders of partner organisations need to offer clear, unambiguous authority for collaboration:

You have to have people at the top giving the message, whether that's about the values of your organisation or whether it's about what you're committed to. Your staff are not going to get excited, are they, if those at the top are not? You want your staff to be excited about what they're doing and feeling good about what they're doing. (Senior executive, Throughcare, Australian Capital Territory)

Executive backing confers political and operational licence to collaborate and offers protection for collaborative spaces:

I think the buy-in from [the] upper-level executive and the capacity and the resources to be able to go out and do our job with the support makes it a lot easier, especially when we're doing something that hasn't been done before. (WHO STOPS, SEA Change, Portland, Victoria)

Ongoing executive backing depends upon regular, and robust, demonstrations of impact. Authorisers need assurance that the collaboration is worth the effort: 
I think it's important that there's a continuation of providing evidence in terms of outcomes back to the executive. So, you can go back and report on the latest findings and how that's looking, [and] benchmark against world-best practice. (WHO STOPS, SEA Change, Portland, Victoria)

\section{Brokers, champions and influencers}

Sometimes, collaboration needs a bit of help. As we have already observed, collaboration is both hard to do and sometimes requires bespoke approaches that take into account the institutional histories and dynamics of particular policy fields. In response, we have seen the emergence of what Daymond (2015: 45) calls 'an industry of cross-sector collaboration practitioners' who work with stakeholders to design and facilitate the implementation of multiparty collaborations. Expert facilitation serves to defuse and reconcile differences and helps to establish credibility and legitimacy (see Chapters 8 and 10).

Independent collaboration brokers can play a positive role by helping to facilitate a shared understanding of the rationale for, and objects of, collaboration. Facilitation by a disinterested third party can help to break down barriers, establish commonalities, address differences and create trust in shared endeavours (Bowden and Ciesielska 2016: 24; Corwin et al. 2012; Bryson et al. 2009a; Daymond 2015; Jupp 2000; Leat 2009).

Prospective collaborations might consider the value of engaging a collaborative intermediary organisation, which Hamann and April (2013: 12) define as 'intermediary organisations that create platforms for deliberation and collaboration between diverse stakeholders'. The necessary capabilities of collaborative intermediary organisationsand indeed of any party acting in a facilitation role-are:

- the ability to translate diverging value frames and perspectives

- an explicit comfort in spaces of high complexity and ambiguity

- the ability to frame conflict and tensions as an opportunity for creativity and innovation (Hamann and April 2013: 20). 
Among the collaborations investigated for our study, Change the Story and WHO STOPS took advantage of expert third-party facilitation in their early stages to help collaboration partners and other stakeholders to arrive at a shared understanding of the problem and a shared vision of the way forward.

Other collaborations have, to some degree, looked to individual champions or influencers to help bring diverse stakeholders to the table. Champions might be people with both influence and formal authority who are able to advocate within organisations on behalf of the collaboration. Influencers, on the other hand, might be people who, while not having formal authority, are well regarded and whose support for collaboration is reassuring to diverse stakeholders:

We've looked at people in positions of authority, so ... councillors, leaders of organisations. Then we've looked at a few of those people that are just change-makers in the community, those people who just make things happen and are known through the community or people that are just well connected so that if it goes up on her Facebook, for example, everyone reads her posts or whatever. (Great South Coast Change)

Importantly, champions are people who embrace opportunities for innovation. Said one interviewee of their primary agency contact:

[He is] working almost against the bureaucratic intent in some ways and bringing a personal approach to the bureaucratic intent. And that's what you need. But bureaucracies don't even realise they need that. So, they employ people who can carry out their bureaucratic intent, and it's just good luck if they get someone who knows how to translate that into a community development function. (CBEM, Emerald, Victoria)

It is also advisable to cultivate multiple collaboration champions because, in a real sense, every person engaged in collaboration has the potential to act as a champion. 


\section{Co-design grounded in lived experience}

Ideally, collaborative aims and actions should be shaped via processes of co-design, including, wherever possible, tapping into the lived experiences of the people and communities that are the focus of the collaboration. One interviewee emphasised the importance of 'allowing multiple opportunities for people to feed back in and reflect':

I think there are certain things you can build in. It is a bit about the design of a process and some of that is about not just saying to people, 'Well, look, you can go away, but we need your feedback by next Friday', for example. It is being able to have a range of different ways in which that feedback is given, checking back in with key stakeholders, having that awareness where there are people who are saying, 'This is not working for me', having an awareness that you might have to do some extra work. I think ... a big part of it is a willingness to participate in a process that is a partnership approach rather than a power dynamic ... If the process had been given in a really rigid way that was lacking in reflection and self-reflection, the whole thing would have crumbled. (Change the Story)

It is worth noting, however, that the concept and practice of co-design are not universally understood. As one interviewee involved in the implementation of the Children's Action Plan put it:

I think co-design would have been a really brand-new buzzword at that time. So, nobody quite knew what that was. When we were all pulled together after the five-minute cup of tea to sort of co-design something, we all turned up not quite knowing what that meant, what it was going to do. Quite a few people after a few weeks sitting left still not quite knowing what it was and what it was going to do ... So, people all came to the table with different ideas of what co-design was and then got frustrated when it wasn't what they thought it was.

Another interviewee offered a slightly more nuanced reflection:

I think co-design is overused and misunderstood, quite frankly ... We should have gone to technical experts in the field to help us be more disciplined around what and how we were trying to do ... When you try and retrofit co-design on something that's already started to evolve, I think you're in trouble. In theory, it's pretty good and I think you should be able to do it, but you've got to start at the grassroots. As soon as you get the idea, start properly, right from the beginning. (Senior official, Children's Action Plan Directorate) 


\section{Corporate memory}

Corporate memory and knowledge are tremendous assets in the collaboration space. Owing to the dynamic, volatile nature of collaborations, collective memory is often not recorded or accorded its true value. Changes in personnel and administrative structures can result in a loss of corporate memory and the substitution of operational orthodoxy in place of the collaborative ethos. There can also be an inherent fragility to executive-level support for collaboration owing to mobility and changing personnel, or changes in the political or operating environment. According to one interviewee, this is especially true for notfor-profit organisations:

Because we're so limited, I don't have someone who comes to these meetings with me because we couldn't afford to have two people sitting around in those meetings. But in government they'll have three or four people at different places in the hierarchy attending the meeting, and that's a good thing. (Throughcare, Australian Capital Territory)

\section{Final observations}

It is worth restating that there is no one-size-fits-all template for collaboration. That said, while all collaborations are unique in that they represent singular responses to a particular set of environmental, historical and institutional circumstances, they also have many features in common. Although there is truth in the proposition that collaboration is a mindset, not a method, effective and sustainable collaboration is underpinned by a suite of practical and strategic activities and practice elements. Our research has revealed a set of broad principles that might be used to guide better practice:

1. Collaboration is about mobilising people and organisations in support of an alternative approach to solving complex problems.

2. It is essential to clearly articulate the problem and demonstrate the case for collaboration.

3. Participants in collaboration need a common understanding of the problem and a common language to frame solutions. 
4. Authorisers need to: a) understand the nature, and likelihood, of any risks associated with collaboration, and b) empower people at the collaboration front line to manage those risks without undue interference.

5. An appropriate governance framework is required to provide assurance to authorisers and others who have a stake in the outcomes of the collaboration.

6. Trust, credibility and legitimacy are the foundations of collaboration, and require open, authentic processes.

7. Authorisers need to understand that collaboration is a time and energy-intensive process and that it will take time for results to become apparent.

8. The case for collaboration needs to be supported by evidence and the path to impact needs to be fully mapped out.

9. Collaboration cannot succeed without strong executive backing in partner organisations.

10. Collaboration brokers, champions and influencers can help to win support for collaboration and sustain ongoing commitment to the purposes and approaches of the collaboration strategy.

11. Collaboration needs to be grounded in lived experience.

12. It is important to value and preserve collaborative 'memory' through attention to succession planning and by documenting the collaboration journey.

\section{Practice considerations}

1. Set out the case for and against collaboration, taking into account the fact that collaboration is not the answer to every problem. Would another form of working together be more appropriate to the task at hand? Is there a shared vision about the task to be undertaken or about the problem that needs to be addressed?

2. Reflect on how historical factors, the intersection of policy spaces, organisational culture and stakeholder relationships contribute to the problem/task; identify what needs to change and assess the potential barriers to change.

3. Identify all relevant stakeholders and potential collaboration partners: who is onside and who needs to be persuaded? Appraise the trustworthiness and credibility of key agencies, institutions and actors from the perspective of major stakeholders. Consider how any trust/credibility deficits might be addressed as well as how established trust/credibility might be leveraged in support of collaboration aims. 
4. Carry out a SWOT (strengths, weaknesses, opportunities and threats) analysis of the key systems, behaviours, processes, institutions and actors that need to change to address the problem or carry out the task.

5. Assess the amount of executive-level backing for a collaborative approach. Assess the potential for a 'zippered' approach that entails peer-to-peer interactions with partner organisations (taking care to spell out the risks of a 'button' approach). Identify potential champions and influencers inside and outside all partner organisations and devise a strategy to mobilise their support for collaboration.

6. Assess whether partner organisations are 'collaboration ready'. What aspects of their organisational culture present barriers to collaboration? What aspects of their culture enhance the prospects of collaboration? Is there an organisational commitment to 'moving the dial' where impediments exist? Do partner organisations have a track record of innovation?

7. Assess authorisers' appetite for risk: Do partner organisations understand the risks associated with collaboration? Do they embrace uncertainty? And are they prepared to accept and learn from failure?

8. Assess the level of decision-making authority brought to the table by collaboration partners. Do participants have the knowledge, skill and authority to participate in decision-making? What resources are available to build the collaborative capacity of collaboration leaders and other participants? Consider engaging expert brokerage/facilitation in the formative stages.

9. Construct a governance framework that will provide: a) clarity about the respective roles and responsibilities of collaboration partners, and b) the assurance necessary for authorisers in partner organisations to embrace the kind of risk associated with collaboration.

10. Think about how impact might be demonstrated over the course of the collaboration, including indirect indicators (for example, evidence of more effective multiparty working) and direct indicators (evidence of improved outcomes). Enlist the assistance of people and institutions with relevant expertise in the formulation of appropriate indicators.

11. Formulate realistic timelines/targets for each stage of the collaborationwherever possible, taking account of learnings from other collaborations—and, using the governance framework, ensure that authorisers and stakeholders know what to expect over the short, medium and longer terms.

12. Develop a communication/consultation strategy and associated protocols to guide engagement with internal stakeholders (that is, within partner organisations) and external stakeholders (that is, individuals, groups and communities likely to be affected by the collaboration) around the rationale, purpose and proposed strategies for collaboration. Ensure consistent, transparent messaging. Actively manage stakeholder expectations. 


\section{References}

Alam, Quamrul, Md Humayun Kabir, and Vivek Chaudhri. 2014. 'Managing infrastructure projects in Australia: A shift from a contractual to a collaborative public management strategy.' Administration \& Society 46(4): 422-49. doi.org/ $10.1177 / 0095399712459728$.

Bowden, Alistair, and Malgorzata Ciesielska. 2016. 'Ecomuseums as crosssector partnerships: Governance, strategy and leadership.' Public Money \& Management 36(1): 23-30. doi.org/10.1080/09540962.2016.1103414.

Bryson, John M., Barbara C. Crosby, Melissa M. Stone, and Emily O. SaunoiSandgren. 2009a. Designing and managing cross-sector collaboration: A case study in reducing traffic congestion. Collaboration: Networks and Partnerships Series Report. Washington, DC: IBM Center for The Business of Government.

Bryson, John M., Barbara C. Crosby, Melissa M. Stone, and Emily O. SaunoiSandgren. 2009b. 'Designing and managing cross-sector collaboration: A case study in reducing traffic congestion.' The Business of Government (Fall/Winter): 78-81.

Butcher, John R., and Benoît Freyens. 2011. 'Competition and collaboration in the contracting of family relationship centres.' Australian Journal of Public Administration 70(1): 15-33. doi.org/10.1111/j.1467-8500.2010.00708.x.

Butcher, John R., and David J. Gilchrist. 2016. The Three Sector Solution: Delivering public policy in collaboration with not-for-profits and business. Canberra: ANU Press. doi.org/10.22459/TSS.07.2016.

Corbin, H., L. Corwin and M.B. Mittelmark. 2012. 'Producing synergy in collaborations: A successful hospital innovation.' The Innovation Journal: The Public Sector Innovation Journal 17(1): Article 5.

Daymond, Jarryd. 2015. Practitioners' perspectives on cross-sector collaborations. Masters thesis, Macquarie University, Sydney.

Edmondson, Amy C. 2011. 'Strategies of learning from failure.' Harvard Business Review 89(4): 48-55, 137.

Garud, Raghu, Arun Kumaraswamy, and Peter Karnøe. 2010. 'Path dependence or path creation?' Journal of Management Studies 47(4): 760-73. doi.org/ 10.1111/j.1467-6486.2009.00914.x.

Hamann, Ralph, and Kurt April. 2013. 'On the role and capabilities of collaborative intermediary organisations in urban sustainability transitions.' Journal of Cleaner Production 50: 12-21. doi.org/10.1016/j.jclepro.2012.11.017. 
Heuer, Mark. 2011. 'Ecosystem cross-sector collaboration: Conceptualizing an adaptive approach to sustainability governance.' Business Strategy and the Environment 20(4): 211-21. doi.org/10.1002/bse.673.

Jones, Dixon D., C.S. Holling, and R. Peterman. 1975. Fail-safe vs. safe-fail catastrophes. IIASA Working Paper, WP-75-93, August. Vienna: International Institute for Applied Systems Analysis.

Jupp, Ben. 2000. Working Together: Creating a better environment for cross-sector partnerships. London: Demos.

Kahane, Adam. 2017. Collaborating with the Enemy: How to work with people you don't agree with or like or trust. Oakland, CA: Berrett-Koehler Publishers.

Keast, Robyn. 2016. 'Integration terms: Same or different?' In Grassroots to Government: Creating joined-up working in Australia, ed. Gemma Carey, pp. 25-46. Melbourne: Melbourne University Press.

Leat, D. 2009. More than Money: The potential of cross-sector relationships. Leicester, UK: Taylor Bloxham.

Merchant, Nilofer. 2011. 'Eight dangers of collaboration.' Harvard Business Review, 1 December.

Pell, Charlotte. 2016. 'Debate: Against collaboration.' Public Money \& Management 36(1): 4-5. doi.org/10.1080/09540962.2016.1103410.

Wilson, Rob, Paul Jackson, and Martin Ferguson. 2016. 'Editorial: Science or alchemy in collaborative public service? Challenges and future directions for the management and organization of joined-up government.' Public Money \& Management 36(1): 1-4. doi.org/10.1080/09540962.2016.1103408. 
This text is taken from Collaboration for Impact: Lessons from the Field, by John Butcher and David Gilchrist, published 2020 by ANU Press, The Australian National University, Canberra, Australia.

doi.org/10.22459/CFI.2020.05 